http://jmscr.igmpublication.org/home/

ISSN (e)-2347-176x ISSN (p) 2455-0450

crossref DOI: https://dx.doi.org/10.18535/jmscr/v8i1.155

Journal Of Medical Science And Clinical Research

\title{
An Assessment of Associated Risk Factors for Retinopathy of Prematurity (ROP) among Neonates of NICU of a Tertiary Care Hospital: A Cohort Study
}

Authors

\section{Dr Saurabh Vijay Doifode ${ }^{1}$, Dr Satish Dattu Ashtekar ${ }^{2 *}$, Dr Shishir Prabhakar Mirgunde ${ }^{3}$, Dr Swati Khot ${ }^{4}$}

${ }^{1}$ Junior Resident, Department of Pediatrics, Government Medical College, Miraj

${ }^{2}$ Associate Professor, Department of Pediatrics, Government Medical College, Miraj

${ }^{3}$ Professor and Head of Department of Peadiatrics, Government Medical College, Miraj

${ }^{4}$ Assistant Professor, Department of Pediatrics, Government Medical College, Miraj

*Correspondence Author

Dr Satish Dattu Ashtekar

Associate Professor, Department of Pediatrics, Government Medical College, Miraj, Maharashtra, India

\section{Abstract}

Background: Due to improved survival of Neonates, Incidence of Retinopathy of Prematurity (ROP) has also increased, which is a serious complication among premature neonates. It can lead to blindness unless recognized early.

Aims \& Objectives: To Estimate the proportion and various associated risk factors of Retinopathy of Prematurity among high risk neonates in the NICU.

Materials and Methods: A Prospective Cohort Study was conducted enrolling all neonates admitted in NICU of a Tertiary Care Hospital from January 2018 to August 2018, with a gestational age <36 weeks and birth weight $<1800$ gms and Neonates with gestational age >36 weeks or birth weight >1800 gms who are exposed to oxygen were included. A total of 96 neonates underwent retinal evaluation by indirect ophthalmoscopy after Fourth postnatal week. Perinatal risk factors for Retinopathy of Prematurity were assessed using statistical analytical tests like Chi Square test and Mid P Exact test.

Results: Out of 96 neonates, 13 neonates (13.54\%) developed ROP; Among them 09 (69.23\%) cases of stage $1,1(7.69 \%)$ case of stage 2, and $3(23.07 \%)$ cases of stage 3. None of the neonates presented ROP at stages 4 or 5. Significant relationship was found between the occurrence of ROP and gestational age, oxygen therapy, blood transfusions, mode of oxygen delivery and sepsis. No association was found between the occurrence of ROP and gender, mode of delivery, birth weight, respiratory distress syndrome, patent ductus arteriosus, birth asphyxia, IUGR babies, intraventricular hemorrhage, meconium aspiration syndrome, phototherapy and duration of oxygentherapy.

Conclusion: The incidence of ROP in this study was 13.54\%; low gestational age, oxygen therapy, blood transfusion and mode of oxygen delivery and sepsis are significant risk factors for ROP occurrence.

Keywords: Prematurity, Retinopathy of Prematurity, Oxygen therapy.

\section{Introduction}

Retinopathy of prematurity (ROP) is an important and Emerging cause of preventable blindness in children. ${ }^{1} 26$ million children are born per year in
India out of which 7.8 million are premature and LBW which are at risk of developing ROP.

Increasing neonatal survival rate with unavailability of standardized neonatal careis 
important cause for increasing incidence of ROP. In India, incidence is reported between $24 \%$ and $47 \%$ among high risk infants. ${ }^{2}$ The incidence of blindness in India is 6.5 per 10000 children based on population based studies from south India. ${ }^{3}$ Early identification and appropriate timely intervention prevent blindness due to ROP and offer child better development. ${ }^{4}$

ROP is a disorder of the immature developing retinal vasculature characterized by cessation of normal vasculogeneis followed by abnormal neovascularization in the retina of premature infants. ${ }^{5}$ These abnormal blood vessels are fragile and can leak or bleed, scarring the retina and pulling it out of position. This causes a tractional retinal detachment, which is the main cause of visual impairment and blindness in ROP. ${ }^{6}$

The stages of ROP according to the International Classification of Retinopathy of Prematurity ${ }^{7}$ (ICROP) describe the retinal findings at the junction between the vascularized and a vascular retina as follows:

Stage 1 : Thin Demarcation line

Stage 2 : An elevated Ridge

Stage 3 : Extraretinal Fibrovascular tissue

Stage 4 : Subtotal retinal detachment

Stage 5 : Total Retinal Detachment.

In addition, Plus disease refers to presence of vascular dilation and tortuosity of posterior retinal vessels in at least 2 quadrants. Preplus disease describes vascular abnormalities of the posterior pole (mild dilatation or arterial tortuosity) that are present but are insufficient for the diagnosis of Plus disease.

Retrolental Fibroplasia now known as Retinopathy of Prematurity was first described with implication of oxygen therapy as the causative agent. However, reports have found ROP in cases without oxygen therapy and even after oxygen therapy, not all develop ROP. ${ }^{8}$ Three factors have shown consistent and significant association with ROP: Low Gestational Age, Low Birth Weight and Prolonged exposure to oxygen. ${ }^{9}$ Other probable risk factors ${ }^{10}$ include Mechanical Ventilation, Sepsis, Intraventricular Hemorrhage, Surfactant Therapy, Anemia, frequent Blood
Transfusions, and Apnea.

The aim of this Prospective Cohort Study was to estimate the proportion of ROP in Preterm infants at the Neonatal Intensive Care Unit (NICU) of Tertiary Care Hospital and to identify the risk factors which predispose to ROP.

\section{Aims \& Objective}

1. To Estimate the proportion of ROP in High Risk Neonates in the NICU.

2. To Identify the Risk Factors which predispose to ROP.

\section{Materials and Methods}

- Study Design: Prospective Cohort Study

- Place: Neonatal intensive Care Unit of Tertiary Care Hospital

- Duration : January 2018 to August 2018

- Study Participants: Considering expected proportion of ROP $35 \% \pm 10 \%$ based on previous study results, sample size calculated was 88 . To avoid attrition we have included 96 Neonates who were admitted in NICU during the study period and fulfilling inclusion criteria.

\section{Inclusion Criteria}

- All Neonates with Gestational Age of 36 weeks or less at birth.

- All Neonates with Birth Weight less than 1800grams.

- Neonates exposed to oxygen therapy with gestational age $>36$ weeks or birth weight $>1800$ grams.

\section{Exclusion Criteria}

- Neonates who died before the first Ophthalmologic examination were excluded.

- Neonates with Congenital Anomalies, Chromosomal Abnormalities \& Inborn Errors of Metabolism.

\section{Procedure}

Neonates fulfilling inclusion and exclusion criteria were selected after taking informed consent from their parents. Detailed perinatal history taken to detect risk factors such as Prematurity, Birth Asphyxia, Meconium Aspiration Syndrome, 
Sepsis. Present history included; the most common symptoms of respiratory distress requiring oxygen therapy, first mode of oxygen therapy, sepsis. The gestational age assessment done by Expanded New Ballard Score.

All enrolled neonates were examined by the Paediatric Ophthalmologist after 4th postnatal week. The eyes were dilated with a combination of tropicamide $0.8 \%$ and phenylephrine 5\% eyedrops applied one hour before the examination. Indirect Ophthalmoscopy with a 20 diopter lens was performed with speculum and Scleral Depression.

The ROP was classified by location on the retina (zone 1-3), and severity (stage 1-5) according to the criteria established by the International Committee for Classification of ROP (ICROP). ${ }^{7}$

After that we examined suspected pre and postnatal risk factors for ROP to identify independent risk factors associated with the development of mild and severe forms of this disease in Tertiary Care Hospital NICU conditions.

\section{Statistical Analysis}

The pre-natal variables were Gestational Age, Birth Weight, Sex, and Mode of delivery. The post-natal variables were Respiratory Distress Syndrome, Birth asphyxia, MAS, oxygen therapy, Phototherapy, Blood transfusion, IVH, PDA, Sepsis. Relative risk was calculated and Pearson chi-square test was applied where ever possible or else Mid $\mathrm{P}$ exact test applied to categorical variables to test whether the relationship exists if any. Data was analysed using open-Epi online statistical software. A p-value of less than 0.05 was considered as Statistically Significant.

\section{Results}

Out of 96 screened Neonates, 13 developed ROP after $4^{\text {th }}$ postnatal week. That means proportion of ROP in our study was $13.54 \%$ among high risk Neonates. Out of 13 ROP cases, 09 (69.23\%) cases were stage $1,1(7.69 \%)$ case stage 2 , and 3 $(23.07 \%)$ cases were stage 3 . None of the studied Neonates presented with stage 4 and stage 5 ROP.
Table 1: Neonatal variables \& ROP among Neonates

\begin{tabular}{|c|c|c|c|c|c|}
\hline \begin{tabular}{|c|}
$\begin{array}{c}\text { Neonatalvari } \\
\text { able }\end{array}$ \\
\end{tabular} & $\begin{array}{l}\text { ROP } \\
\text { n (\%) }\end{array}$ & $\begin{array}{c}\text { Normal } \\
\text { n }(\%)\end{array}$ & Total & $\begin{array}{c}\text { RR } \\
(95 \% \mathrm{CI}) \\
\end{array}$ & p value \\
\hline \multicolumn{6}{|l|}{ Gender } \\
\hline Male & $07(13.2)$ & $46(86.8)$ & 53 & & \multirow[b]{2}{*}{$\mathrm{p}=0.91$} \\
\hline Female & $06(13.9)$ & $37(86.1)$ & 43 & $\begin{array}{c}0.94 \\
(0.34,2.60) \\
\end{array}$ & \\
\hline \multicolumn{6}{|c|}{ Mode of Delivery } \\
\hline NVD & $06(12.5)$ & $42(87.5)$ & 48 & $\begin{array}{c}0.69 \\
(0.25,1.90)\end{array}$ & \multirow{2}{*}{$\mathrm{p}=0.48$} \\
\hline LSCS & $07(14.6)$ & $32(66.7)$ & 48 & & \\
\hline \multicolumn{6}{|c|}{ Birth Weight (kg) } \\
\hline$\leq 1 \mathrm{~kg}$ & $01(33.3)$ & $02(66.7)$ & 03 & \multirow{4}{*}{$\begin{array}{c}2.08 \\
(0.76,5.64) \\
\end{array}$} & \multirow{4}{*}{$* \mathrm{p}=0.17$} \\
\hline \begin{tabular}{|l|}
$1.01-1.49 \mathrm{~kg}$ \\
\end{tabular} & $05(20)$ & $20(80)$ & 25 & & \\
\hline $1.5-1.8 \mathrm{~kg}$ & $05(15.6)$ & $27(84.4)$ & 32 & & \\
\hline$\geq 1.8 \mathrm{~kg}$ & $02(5.6)$ & $34(94.4)$ & 36 & & \\
\hline \multicolumn{6}{|l|}{ Maturity } \\
\hline$<32$ wk & $04(33.3)$ & $08(66.7)$ & 12 & & \multirow{4}{*}{$* \mathrm{p}=0.001$} \\
\hline $32-34 \mathrm{wk}$ & $06(30)$ & $14(70)$ & 20 & & \\
\hline $\begin{array}{c}34-36 \\
\text { Wks }\end{array}$ & $01(3.8)$ & $25(96.2)$ & 26 & $6.6(1.97,22.54)$ & \\
\hline$>36 \mathrm{wks}$ & $02(5.3)$ & $36(94.7)$ & 38 & & \\
\hline TOTAL & $13(13.5)$ & $83(86.5)$ & 96 & & \\
\hline \multicolumn{6}{|c|}{ * After pooling data Mid-P exact test applied } \\
\hline
\end{tabular}

As per Table 1. No association was found between the occurrence of ROP and gender, mode of delivery and birth weight. But Low Gestational age (upto 34 weeks) has 6.6 times more risk of getting ROP than others and it was statistically significant.

$33.3 \%$ of Neonates with $<32$ weeks of gestational age developed ROP out of which $50 \%$ developed stage $1 \mathrm{ROP}$ and $50 \%$ developed stage 3ROP.

$30 \%$ of Neonates with 32-34 weeks of gestational age developed ROP out of which $66.7 \%$ developed stage 1 ROP, $16.7 \%$ developed stage 2 ROP and $16.7 \%$ developed stage 3 ROP.

$3.84 \%$ of Neonates with $>34$ weeks of gestational age developed ROP all of them developed stage 1 ROP. Whereas $5.26 \%$ of Neonates with >36 weeks of gestational age developed ROP all of them developed stage 1 ROP.

Table 2: Association of occurrence of ROP with treatment modalities given to neonates

\begin{tabular}{|c|c|c|c|c|c|}
\hline & $\begin{array}{l}\text { ROP } \\
\text { n(\%) }\end{array}$ & $\begin{array}{c}\text { Normal } \\
\text { n }(\%)\end{array}$ & $\begin{array}{c}\text { Total } \\
\text { No. }\end{array}$ & $\begin{array}{c}\text { RR } \\
(95 \% \mathrm{CI})\end{array}$ & p value \\
\hline \multicolumn{6}{|l|}{ Phototherapy } \\
\hline Not given & $07(16.3)$ & $36(83.7)$ & 43 & $\begin{array}{c}1.43 \\
(0.52,3.96)\end{array}$ & \multirow[b]{3}{*}{${ }^{*} \mathrm{p}=0.48$} \\
\hline SSPT & $04(12.5)$ & $28(87.5)$ & 32 & \multirow[b]{2}{*}{$1.3(0.26,6.53)$} & \\
\hline DSPT & $02(9.5)$ & $19(90.5)$ & 21 & & \\
\hline \multicolumn{6}{|c|}{ Blood Transfusion } \\
\hline Received & $05(27.7)$ & $13(72.2)$ & 18 & \multirow[b]{2}{*}{$2.70(1.0,7.3)$} & \multirow[b]{2}{*}{$* * \mathbf{p}=\mathbf{0 . 0 7}$} \\
\hline Not received & $08(10.3)$ & $70(89.7)$ & 78 & & \\
\hline \multicolumn{6}{|c|}{ Oxygen therapy } \\
\hline Given & $12(18.5)$ & $53(81.5)$ & 65 & \multirow[b]{2}{*}{$5.7(0.77,42.0)$} & \multirow{3}{*}{$* * \mathbf{P}=\mathbf{0 . 0 3}$} \\
\hline Not given & $01(3.2)$ & $30(96.8)$ & 31 & & \\
\hline TOTAL & 13 & 83 & 96 & & \\
\hline
\end{tabular}


In table 2 when tried to find out association of occurrence of ROP with treatment modalities given to neonates, no association seen between occurrence of ROP with type of phototherapy.

Occurrence of ROP observed 2.7 times more with blood transfusion although it wasn't statistically significant. $27.7 \%$ of those who received blood transfusion developed ROP out of which $60 \%$ developed stage 1 ROP and $40 \%$ developed stage 3 ROP.

Oxygen therapy was significantly associated with occurrence of ROP among neonates almost 5.7 times more than those who didn't receive oxygen therapy though it was not consistent. $18.5 \%$ of babies who received oxygen therapy developed ROP out of which $66.7 \%$ developed stage 1 ROP, $8.3 \%$ developed stage 2 ROP and $25 \%$ developed stage 3 ROP.

Table 3: Association of occurrence of ROP and duration and mode of oxygen therapy given to neonates

\begin{tabular}{|c|c|c|c|c|c|}
\hline $\begin{array}{c}\text { Duration of } \\
\text { oxygen } \\
\text { Therapy } \\
\end{array}$ & $\begin{array}{l}\text { ROP } \\
\text { n(\%) }\end{array}$ & $\begin{array}{c}\text { Normal } \\
\mathbf{n}(\%)\end{array}$ & $\begin{array}{c}\text { Total } \\
\text { no. }\end{array}$ & $\begin{array}{c}\text { RR } \\
(95 \% \mathrm{CI})\end{array}$ & p value \\
\hline up to 3 days & 05 (15.6) & $27(84.4)$ & 32 & & \multirow{3}{*}{$* \mathrm{p}=0.23$} \\
\hline $4-5$ days & $03(15)$ & $17(85)$ & 20 & & \\
\hline$>5$ days & 04 (36.4) & 09 (63.6) & 13 & $2(0.71,5.63)$ & \\
\hline TOTAL & 13 & 83 & 65 & & \\
\hline $\begin{array}{c}\text { Mode of } \\
\text { oxygen } \\
\text { Therapy }\end{array}$ & & & & & \\
\hline Hood & 03(11.1) & $\begin{array}{l}24(88.9) \\
\end{array}$ & 27 & & \multirow[b]{3}{*}{${ }^{*} \mathrm{p}=0.03$} \\
\hline CPAP & 05(16.7) & $25(83.3)$ & 30 & & \\
\hline $\begin{array}{l}\text { Mechanical } \\
\text { Ventilator }\end{array}$ & $04(50)$ & $04(50)$ & 08 & $\begin{array}{c}3.56 \\
(1.38,9.16)\end{array}$ & \\
\hline TOTAL & 13 & 83 & 65 & & \\
\hline
\end{tabular}

Acc to table 3, Duration of oxygen therapy was not associated with occurrence of ROP. However $15.6 \%$ of babies who received oxygen upto 3 days developed stage 1 ROP.15\% of babies who received oxygen therapy for 3-5 days developed ROP out of which $66.66 \%$ developed stage 1 ROP and $33.33 \%$ developed stage 3 ROP. 36.36 $\%$ of babies who received oxygen for $>5$ days developed ROP out of which $25 \%$ developed stage 1 ROP, $25 \%$ developed stage 2 ROP and 50 $\%$ developed stage 3 ROP.

Mode of oxygen delivery was significantly associated with occurrence and severity of ROP. Almost 3.5 times more risk of ROP observed among neonates who received oxygen through mechanical ventilator than other mode. $11.11 \%$ of babies who received oxygen by hood developed ROP all of them developed stage 1 ROP.

$16.7 \%$ of babies who received oxygen by CPAP developed ROP. Out of which $80 \%$ developed stage 1 ROP and $20 \%$ developed stage 3 ROP.

$50 \%$ of babies who received oxygen by mechanical ventilation developed ROP out of which $25 \%$ developed stage 1 ROP, $25 \%$ developed stage 2 ROP and $50 \%$ developed stage 3 ROP.

Table 4: Type of morbidity and ROP

\begin{tabular}{|l|c|c|c|c|l|}
\hline Diagnosis & ROP & Normal & $\begin{array}{c}\text { No of } \\
\text { patients }\end{array}$ & $\begin{array}{c}\text { RR } \\
(\mathbf{9 5 \%} \text { CI })\end{array}$ & p value \\
\hline SEPSIS & $04(33.3)$ & 08 & 12 & $\begin{array}{c}3.59 \\
(1.30,9.89)\end{array}$ & $* \mathrm{p}=0.04$ \\
\hline RDS & $05(22.7)$ & 17 & 22 & & \\
\hline $\begin{array}{l}\text { BIRTH } \\
\text { ASPHYXIA }\end{array}$ & $03(0.3)$ & 07 & 10 & & \\
\hline IUGR & $01(4.5)$ & 21 & 22 & & \\
\hline MAS & $00(0)$ & 05 & 05 & & \\
\hline $\begin{array}{l}\text { OTHERS } \\
\text { PDA,IVH,CHD }\end{array}$ & $00(0)$ & 25 & 25 & & \\
\hline TOTAL & $\mathbf{1 3}$ & $\mathbf{8 3}$ & $\mathbf{9 6}$ & & \\
\hline *After pooling data sepsis vs other morbidities, Mid-P exact test applied \\
\hline
\end{tabular}

According to table 4, Sepsis was significantly associated with occurrence of ROP. Almost 3.5 times more risk of ROP observed in neonates with sepsis than other morbidities. $33.3 \%$ of neonates diagnosed with sepsis developed ROP out of which $75 \%$ developed stage $1 \mathrm{ROP}$ and $25 \%$ developed stage 3ROP

No association was seen between occurrence of ROP with Respiratory Distress Syndrome, Birth Asphyxia, Meconium Aspiration Syndrome, IUGR Babies, Patent Ductus Arteriosus, Intraventricular Haemorrhage, Congenital Heart Diseases.

Table 5 Outcome of ROP after follow up

\begin{tabular}{|l|l|l|}
\hline ROP & & Follow up \\
\hline $\begin{array}{l}\text { Grade } \\
\text { 1ROP }\end{array}$ & 09 & $\begin{array}{l}\text { All 09 cases spontaneously regressed on } \\
\text { follow up. }\end{array}$ \\
\hline $\begin{array}{l}\text { Grade 2 } \\
\text { ROP }\end{array}$ & 01 & $\begin{array}{l}\text { Patient was lost to follow up after 1 } \\
\text { screening. }\end{array}$ \\
\hline $\begin{array}{l}\text { Grade 3 } \\
\text { ROP }\end{array}$ & 03 & $\begin{array}{l}\text { All 3 neonates received laser } \\
\text { photocoagulation therapy and regressed on } \\
\text { follow up. }\end{array}$ \\
\hline
\end{tabular}

\section{Discussion}

- In this study we found Low-Gestational Age is significantly associated with occurrence of ROP, it is the most important risk factor in ROP. Similar observations made by Shah et al 
11, Karna et al ${ }^{12}$ and Fortes et al ${ }^{13}$ in their respective studies. This was explained by immaturity of retinal neural and vascular development at birth in preterms and therefore retinal vulnerability to oxidative damage and to a number of perinatal factors which include Hyperoxia and Hypoxia, Blood Transfusions, and Sepsis.

- Oxygen Therapy was an independent risk factor for the development of ROP. We found a significant relationship between the occurrence of ROP and use of Oxygen. In our study we found that duration of oxygen therapy is insignificant for development of ROP which was in agreement with the results of Dutta et al ${ }^{14}$ However few studies reported that a duration of oxygen therapy was a significant risk factor for development of ROP. This could be because of change of setting and other Perinatal and Postnatal factors.

- Low Gestational Age and Mechanical Ventilation were associated with severity of ROP which was in agreement with results of Wang et al ${ }^{15}$, Mojgan Bayat-Mokhtari et al. ${ }^{16}$

- In this study, we found that Sepsis was significantly associated with the development of ROP. This was in agreement with Shah et $\mathrm{al}^{11}$ and Vinekar et al ${ }^{17}$., which may be due to the effect of endotoxins on retinal blood vessels. On the other hand, this was in disagreement with the results of Chaudhari et al ${ }^{18}$, and Smith et al ${ }^{19}$.

\section{Conclusion}

- Survival of High Risk Newborn is at most priority of Pediatrician. However clinicians should be aware of the presence of the additional risk factors while managing and monitoring of preterm infants. The analysis of risk factors for ROP development will help clinicians to predict it in high risk infants.

- Regular Follow Up and timely Retinal Screening of High-Risk Preterm infants is important to identify ROP in earlier stages. It will prevent the development of advanced ROP by adequate intervention.

- Since ROP may produce serious sequelae including complete blindness, all efforts must be made to prevent the development of advanced ROP through changes in the neonatal care, control of sepsis, judicious use of oxygen therapy and improvement in detection of threatening ROP markers.

\section{Limitation}

This is a time bound study and conducted on a relatively small sample size. In future, these limitations can be overcome by planning a MultiCentric study with larger sample size.

\section{Acknowledgement}

We sincerely acknowledge our Dean for her continuous guidance and support in conducting this study.

\section{Bibliography}

1. Park K. Park's textbook of Preventive And Social Medicine : $25^{\text {th }}$ Edition2019.

2. Piyush Gupta, Menon Ramji Lodha. PG Textbook of Peadiatrics, Volume 1: $2^{\text {nd }}$ edition 2018.

3. Murthy KR , Murthy PR, Shah DA, Nandan MR, S NH,BenakappaN. Comparison of profile of retinopathy of prematurity in semi urban/rural and urban Nicus in Karnataka, India. Br J Opthalmol 2013;97:687-9.

4. Azad R, Chandra P, authors. Retinopathy of prematurity. $\mathrm{J}$ Indian Med Assoc. 2005;103:370-2.

5. Eric C Eichenwald, Anne R. Hansen, Camilia R. Martin, Ann R. Stark authors. Cloherty and starks manual of neonatal care : $8^{\text {th }}$ edition South Asianedition.

6. Carlos A. Medina, Manual of Retinal Diseases : A Guide to Diagnosis and Management.

7. The International Classification of Retinopathy of Prematurity revisited Arch Opthalmol. 2005;123:991-9. 
8. Zia Chaudhary, M Vanathi authors : Paediatric Opthalmology.

9. Terry TL; Extreme prematurity and fibroblastic overgrowth of persistent vascular sheath behind each crystalline lens. Preliminary Reports. Am J Opthalmo., 1942;25:203-204.

10. Brad Bowling author: Kanksi's Clinical Opthalmology, A Systematic Approach , $8^{\text {th }}$ Edition.

11. Shah VA, Yeo CL, Ling YL, authors. Incidence, risk factors of retinopathy of prematurity among very low birth weight infants in Singapore. Ann Acad Med Singapore.2005;34:169-78.

12. Karna P, Muttineni J, Angell L, authors. Retinopathy of prematurity and risk factors: A prospective cohort study. BMC Pediatr. 2005;5:18.

13. Fortes JB, Eckert GU, Procianoy L, authors. Incidence and risk factors for retinopathy of prematurity in very low and in extremely low birth weight infants in a unit-based approach in southern Brazil. Eye (Lond). 2009;23:25-30.

14. Dutta S, Alaraop S, Narang A, authors. Risk factors of threshold retinopathy of prematurity. IndianPediatr.2004;41:665-71.

15. Zong-Hua Wang, Yao-yuli and Zhi-Min Liu authors. Birth weight and gestational age on ROP in Discordant twins inChina.

16. Mojgan Bayat-Mokhtari, MD, narjes Pishva, MD authors. Incidence and Risk Factors of Retinopathy of Prematurity among Preterm Infants inShiraz/Iran.

17. Vinekar A, Dogra M, Sangtam T, authors. Retinopathy of prematurity in Asian Indian babies weighting greater than 1250 gram at birth; ten years data from tertiary care center in a developing country. Indian $\mathbf{J}$ Ophthalmol.2007;55:331-6.

18. Chaudhari S, Patwardhan V, Vaidya U, authors. Retinopathy of prematurity in a tertiary care center, incidence, risk factors and outcomes. Indian Pediatr. 2009;46:21924.
19. Smith LE, author. Pathogenesis of retinopathy of prematurity. Acta Paediatr Suppl. 2002;91:26. 